\title{
DEVELOPMENT OF A VIRTUAL ENVIRONMENT FOR TEACHING AND LEARNING BIOMEDICAL TECHNIQUES AND EQUIPMENT FOR THE STUDY OF HUMAN PATHOGENS
}

\author{
A. Peña-Fernández ${ }^{1}$, S. Fenoy ${ }^{2}$, M.D. Evans ${ }^{1}$, T. Sgamma ${ }^{1}$, C. Hurtado ${ }^{2}$, \\ F. Izquierdo', M. Randles ${ }^{1}$, C. Young ${ }^{1}$, L. Acosta ${ }^{3}$, C. Del Aguila ${ }^{2}$ \\ ${ }^{1}$ De Montfort University, School of Allied Health Sciences (UNITED KINGDOM) \\ ${ }^{2}$ Universidad San Pablo CEU, Facultad de Farmacia (SPAIN) \\ ${ }^{3}$ Universidad Miguel Hernández de Elche (SPAIN)
}

\begin{abstract}
An international innovative teaching group from different EU Universities (De Montfort University, Leicester, UK; University of San Pablo CEU, Madrid, Spain; University of Miguel Hernandez, Elche, Spain) and biomedical scientists registered by the Health and Care Professions Council (HCPC, UK) are developing a complete e-learning package in medical parasitology for undergraduate and postgraduate students that study Health Sciences. This package, named DMU e-Parasitology, is accessible through the DMU website (http://parasitology.dmu.ac.uk) and will present different modules including a virtual laboratory module for the study of traditional and novel biomedical laboratory techniques and equipment for detecting, identifying and studying human pathogens, specifically parasites. These techniques could also be potentially used to study other pathogens such as bacteria or viruses. The virtual biomedical laboratory is under development, but is available in the DMU website here: http://parasitology.dmu.ac.uk/learn/laboratory.htm. To develop this new module of the DMU eParasitology, we are using Storyline 360 software and the scaffolding and methods used to build the theoretical module (Peña-Fernández et al., 2017) [1]. To facilitate the navigation, study and comprehension of the final user, we have divided the virtual laboratory into a series of sub-sections that include different units; the sub-sections so far are: microscopes (with units such as the electron microscope); molecular biology (e.g. polymerase chain reaction and gel electrophoresis); biological safety cabinets and cell/parasite culture; biochemical and immunological techniques (e.g. magnetic immunoseparation); histology (e.g. microtome) and staining techniques (e.g. Kinyoun staining). The virtual laboratory units are highly interactive and present short videos of academics and/or technicians working in real conditions with the different laboratory equipment such as a thermocycler, a microtome, or a biological safety cabinet, as well as performing a specific technique such as a staining to determine pathogens. Therefore, the user of this virtual environment will receive a complete and "real" experience of the work in a biomedical laboratory. The DMU e-Parasitology package, and specifically its virtual laboratory environment, could help technicians and students across the world to learn how to work in a biomedical laboratory as well as to perform techniques to identify and diagnose human pathogens such as microsporidia or Plasmodium spp. Thus, the virtual resource is supported by a virtual library that includes a real collection of clinical slides that will provide the user with the functionality of a light and/or an immunofluorescence microscope. In conclusion, the virtual laboratory may serve as a high quality and reliable on-line environment for the learning of techniques and equipment. These resources can be used to improve the learning of undergraduate and postgraduate students of human health sciences as well as to develop CPD training. Moreover, the virtual laboratory module may impact in the teaching of laboratory techniques and skills in developing countries due to their limited resources. This communication will explore the design and development of the virtual laboratory environment that will be publicly accessible by the end of 2018 .
\end{abstract}

Keywords: DMU e-Parasitology, virtual laboratory, biomedical laboratory, medical parasitology.

\section{INTRODUCTION}

Future practitioners and related health care professionals will need to gain a strong scientific background including knowledge on biomedical laboratory techniques and equipment for translational medicine. Such training would be translated in better laboratory diagnostic procedures and thus medical treatment and prognostic information for the patient [2]. However, medical education is facing different challenges to appropriately deliver this type of overall education including lack of access to 
new laboratory techniques to students due to costs, time and space constraints as well as lack of specialism.

As a result, our international teaching innovation group from different European Universities including De Montfort University (DMU, Leicester, UK) and the Spanish Universities of San Pablo CEU (USPCEU, Madrid) and Miguel Hernández de Elche (Alicante), is developing a complete on-line package for teaching and learning parasitology in collaboration with clinicians and practising biomedical scientists from the UK National Health Service. This package, named DMU e-Parasitology [1,3] (Figure 1), will be publicly available on the DMU website by the end of 2018 and will include a complete virtual biomedical laboratory which aims to facilitate the learning of a comprehensive range of biomedical laboratory techniques and equipment used in any specialised parasitology laboratory to study human parasites. The DMU e-Parasitology virtual laboratory component will not only cover the foundations of a current biomedical laboratory but also more specialised techniques and methods used for the study of human parasites, including emerging parasites.

\subsection{Aims}

The aims of this paper is to provide an overview of the design and scaffolding of the virtual laboratory and describe the strategies that we are following to build it as an engaging teaching and learning resource to facilitate the teaching of techniques, methods and equipment for the study of human parasites.

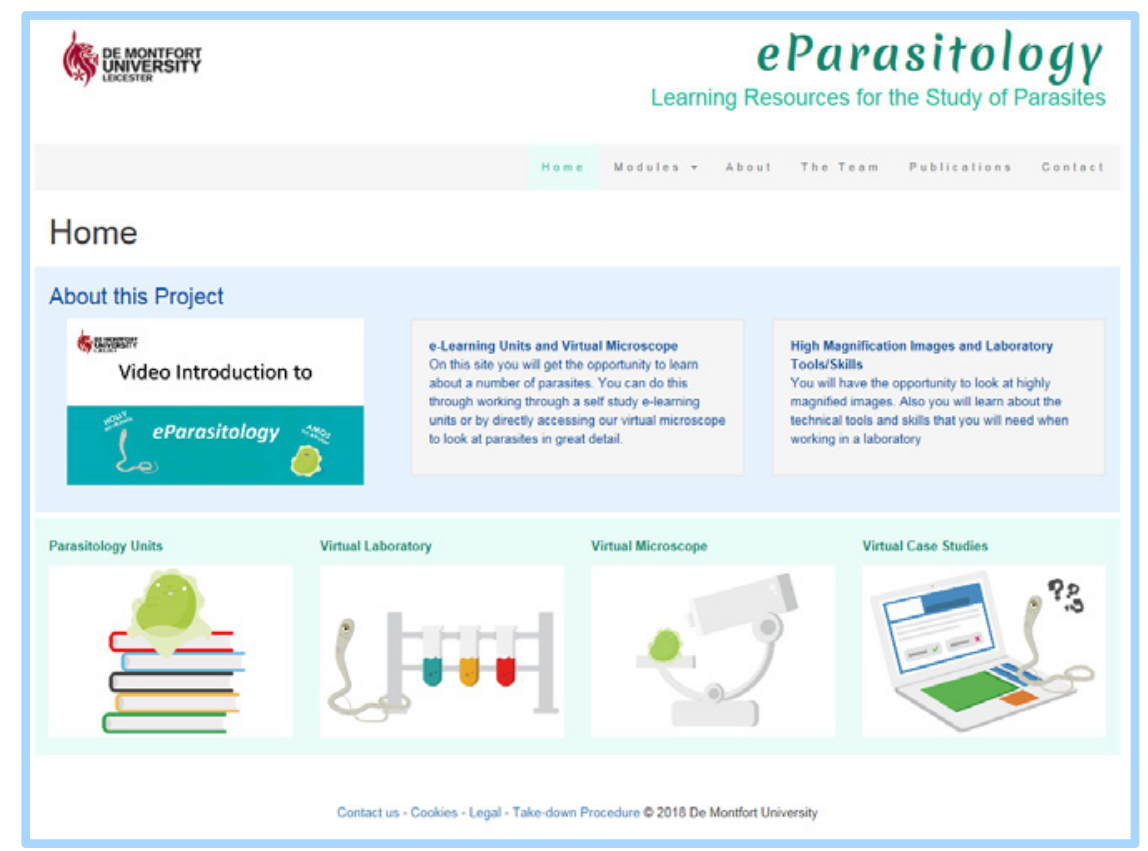

Figure 1. Overview of DMU e-Parasitology main page in which the four modules can be seen (Image courtesy of DMU). Available at: http://parasitology.dmu.ac.uk/

\section{THE DMU E-PARASITOLOGY VIRTUAL LABORATORY}

The virtual biomedical laboratory (Figure 2) is publicly available throughout the DMU e-Parasitology webpage or directly in the DMU website here: http://parasitology.dmu.ac.uk/learn/laboratory.htm. It is envisaged that this resource will be completed by no later than 2019 .

\subsection{Methods}

The main scaffolding of the virtual laboratory and the different units are being built using Storyline 360 software, following previous experience gained during the development of the theoretical model unit of the Toxocara parasite [1]. Briefly, academics from the three participating universities involved in the project were allocated different unit(s) to develop according to their expertise and research background; and they completed a Powerpoint or Word document as a storyboard with all the necessary information together with photographs and/or diagrams to enable developers to build the 
relevant unit. Units are being created at DMU using a pre-defined design that provides consistency to the final product; diagrams and graphic designs are also developed by graphic designers as appropriate.

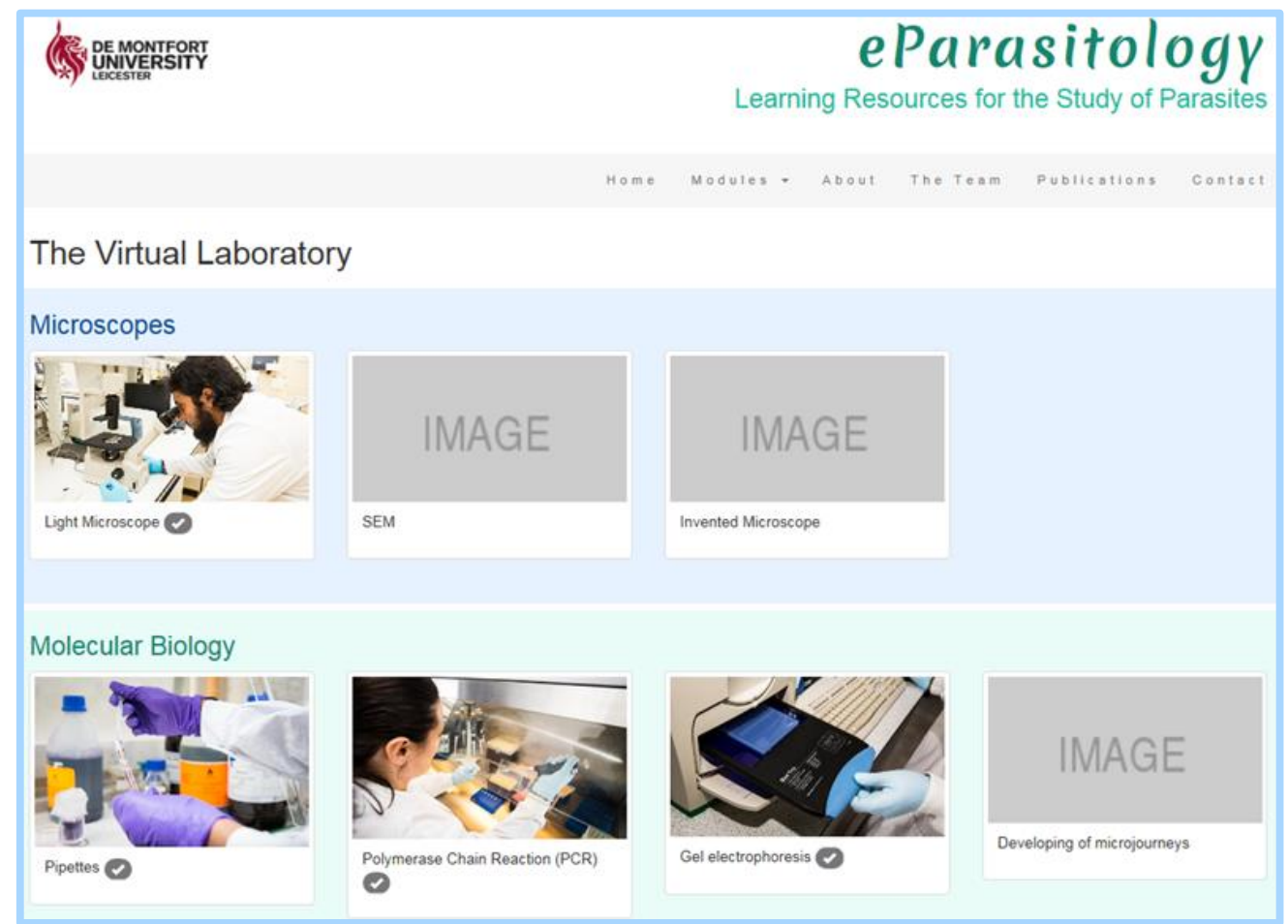

Figure 2. Overview of the DMU e-Parasitology's virtual laboratory main page (Image courtesy of DMU). Available at: http://parasitology.dmu.ac.uk/learn/laboratory.htm

Additionally, and particularly relevant for this module owing to its high practical component, videos of academics and/or technicians working in real conditions with the equipment or the laboratory technique considered in each are being produced (brands are conveniently avoided when making the recording and/or deleted if unavoidable). The videos will provide a complete picture to the final user of this resource of how to perform that technique or use that equipment and will facilitate their learning, reflection and comprehension. The videos are short, no longer than a few minutes $(<2$ min), and are appropriately inserted within each unit so the user can optionally play and visualise them when navigating throughout the unit. Finally, videos are presented with audio and subtitles. Scripting for subtitles and use of audio files are being created following a small script and/or instructions provided by the academics involved in the unit development, to enhance student engagement and inclusivity.

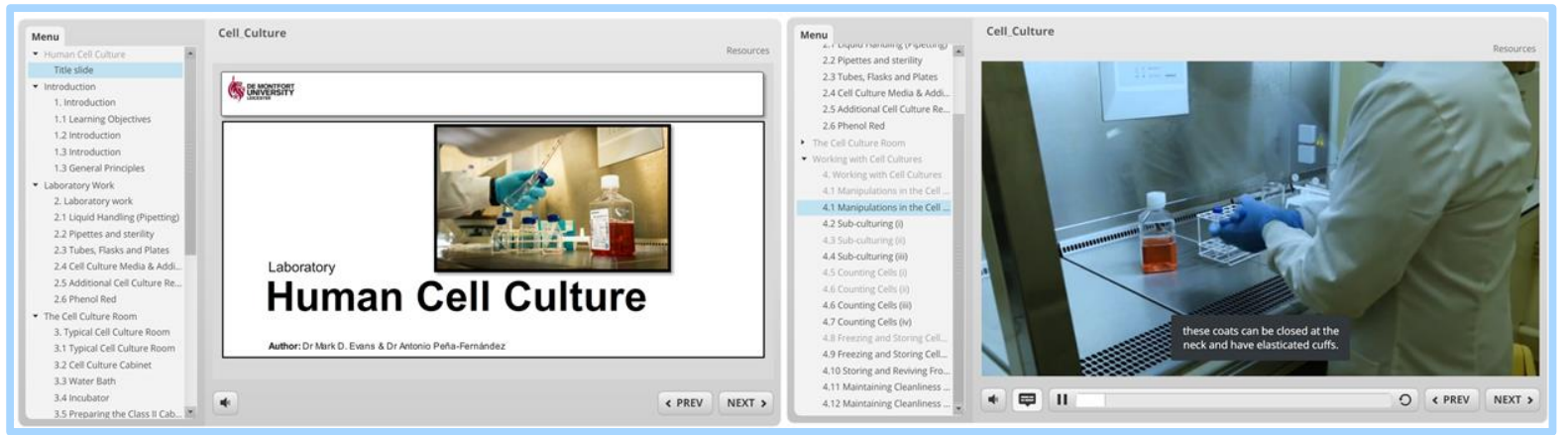

Figure 3. Overview of the DMU e-Parasitology cell culture unit showing one of the videos (Image courtesy of DMU; Evans and Peña-Fernández, 2018 [4]). Available at: http://parasitology.dmu.ac.uk/learn/lab/cell_cultures/story_flash.html 
Finally, the virtual laboratory units will provide a range of short formative assessments to facilitate the self-evaluation of users' learning; and will be optional. Questions and mini-quizzes will be introduced at different points throughout the unit to maintain user engagement.

\subsection{Structure}

The virtual laboratory module, similar to the other modules/sections of the DMU e-Parasitology package, has been sub-divided in sub-sections to facilitate the navigation and enhance their use and comprehension (some of these sections can be seen in Fig. 2). To date, five sub-sections have been initially prepared (although they may change throughout their development), which include different units as follows:

a) Microscopes: with different units that will explain the normal light and inverted microscope as well as more sophisticated microscopes such as the scanning electron microscope.

b) Biochemical and Immunological techniques: will contains different units for routine biochemical tests such as protein purification; and others relevant for the study of parasites related to immunological techniques.

c) Molecular biology: this sub-section will present a range of units that explain the use of laboratory pipettes and how to perform a polymerase chain reaction or analyse nucleic acids using gel electrophoresis.

d) Cell and parasite culture unit: which will present a range of materials related to the culture of cells and parasites as well as how to work with a biological safety cabinet class II.

e) Staining techniques: this sub-section will present the most relevant staining techniques for detecting parasites in a clinical and/or environmental sample.

A sixth sub-section to cover histology and the use of the microtome is under discussion and may be also created in this phase of the project to enhance the robustness of the future virtual environment.

\subsection{Model unit}

A complete unit with all the elements described above, which corresponds to the human cell culture unit (Fig. 3; http://parasitology.dmu.ac.uk/learn/lab/cell_cultures/story_flash.html; [4]), is being used as a model unit to develop the virtual laboratory module. Detailed information about this unit has been previously published by our group [5]. The unit will be tested with current second year BSc Biomedical Science students enrolled in the module "Research and Diagnostic Techniques" some of whom will voluntarily attend a summer session on cell culture that is being organised by $\mathrm{Dr}$ Neenu Singh at DMU. Students will be asked to complete this e-learning unit prior to attend the lab session and will provide feedback once the practical is completed to gain students' information about the suitability of the unit for learning how to work with cells in a cell culture unit. Feedback will be used to develop/further refine the module and general feedback applied to the development and refinement of other units in the virtual laboratory module.

\section{PRELIMINARY RESULTS OF STUDENTS' OPINION ABOUT THE VIRTUAL LABORATORY}

Although results on the suitability of the DMU e-Parasitology virtual laboratory are to be gained later this year after comprehensive student feedback from the three participating EU universities, including the above focus group created to analyse the human cell culture unit, we are able to extract some preliminary feedback and a general overview from the previous focus groups. These focus groups were created to assist development and refinement of a model unit for two other sections/modules of the DMU e-Parasitology: theoretical and case study modules. The feedback related to the developing the virtual laboratory module and preliminary opinion on the overall package for those two groups are described below:

- Focus group for theoretical module: $3^{\text {rd }}$ year Pharmacy and Biotechnology students at USPCEU in 2016/17; [1]). Despite the fact that the virtual laboratory was in early stages when tested with these students, they enjoyed the experience with DMU e-Parasitology $(66.7 \%$ agreed; $33.3 \%$ strongly agreed).

- Focus group for case study module: postgraduate students enrolled in MSc Advanced Biomedical Science at DMU in 2017/18; [6]). These students indicated that the overall package 
is interactive ( $71.4 \%$ agreed, 28.57 strongly agreed) and the design of the virtual laboratory (100\% agreed) was suitable.

\section{CONCLUSIONS}

The DMU e-Parasitology virtual laboratory component could aid human health students to gain significant knowledge of laboratory techniques, equipment and methods for the study of human parasites as well as gaining some knowledge about how to work in a biomedical laboratory by promoting self-learning and overcoming barriers of time, space, equipment and resources. This would assist students from diverse backgrounds to acquire basic biomedical and parasitology laboratory work skills that are essential for future health care professionals. Finally, this resource could assist academics by teaching relevant aspects of biomedical/parasitology laboratory practical work that would otherwise be difficult to provide due to time constraints, number of students and/or resource limitations.

\section{ACKNOWLEDGEMENTS}

The authors would like to express their sincere appreciation to Jonathan Coope and Maxine Armstrong (DMU) for their work in software development of DMU e-Parasitology; DMU Frontrunner intern Mr. Marek Kowalik for photography and video production; the Teaching Innovation Project Fund at De Montfort University (scheme 2015-16) to fund this project, awarded to Dr. Peña-Fernández.

\section{REFERENCES}

[1] Peña-Fernández A., Ollero MD., Fenoy S., Magnet A., Izquierdo F., Peña MÁ., Bornay F., Acosta L., Parker LA., Sgamma T., Del Águila C. Creating a model module for the novel resource DMU e-Parasitology. ICERI2017 Proceedings; 1599-1604. ISBN: 978-84-697-6957-7.

[2] Makransky G., Bonde MT., Wulff JS., Wandall J., Hood M., Creed PA., Bache I., Silahtaroglu A., Nørremølle A. Simulation based virtual learning environment in medical genetics counseling: an example of bridging the gap between theory and practice in medical education. BMC Med Educ 2016; 16:98.

[3] Peña-Fernández A., Magnet A., Acosta L., Evans MD., Fenoy MS. Developing a digital environment for teaching and learning parasitology. Higher Education Academy STEM conference 2018, Newcastle, UK, 31st Jan - 1st Feb 2018. Oral presentation. Available at: https://www.heacademy.ac.uk/knowledge-hub/developing-digital-environment-teaching-andlearning-parasitology-stem-conference

[4] Evans MD and Peña-Fernández A. Human cell culture. DMU e-Parasitology, 2018. Available at the DMU e-Parasitology website here: http://parasitology.dmu.ac.uk/learn/lab/cell_cultures/story_flash.html [accessed 10/05/2018]

[5] Peña-Fernández A., Hurtado C., Del Águila C., Evans M. Developing resources for teaching and learning cell and parasite culture within the DMU e-Parasitology package. ICERI2017 Proceedings; 7117-7122. ISBN: 978-84-697-6957-7.

[6] Peña-Fernández A., Magnet A., Peña MA. Focus group to create a virtual case study model unit for the DMU e-Parasitology. EduLearn2018 Proceedings; submitted for publication. 